\title{
(6) OPEN ACCESS \\ Premature small for gestational age infants fed an exclusive human milk-based diet achieve catch-up growth without metabolic consequences at 2 years of age
}

\author{
Chonnikant Visuthranukul, ${ }^{1,2,3,4}$ Steven A Abrams, ${ }^{5}$ Keli M Hawthorne, ${ }^{5}$ \\ Joseph L Hagan, ${ }^{1}$ Amy B Hair ${ }^{1}$
}

${ }^{1}$ Section of Neonatology, Department of Pediatrics, Baylor College of Medicine, Texas Children's Hospital, Houston, Texas, USA

2USDA/ARS Children's Nutrition Research Center, Department of Pediatrics, Baylor College of Medicine, Houston, Texas, USA ${ }^{3}$ Section of Nutrition, Department of Pediatrics, King Chulalongkorn Memorial Hospital, The Thai Red Cross Society, Bangkok, Thailand ${ }^{4}$ Pediatric Nutrition STAR, Department of Pediatrics, Faculty of Medicine, Chulalongkorn University, Bangkok, Thailand ${ }^{5}$ Department of Pediatrics, Dell Medical School, University of Texas at Austin, Austin, Texas, USA

\section{Correspondence to} Dr Amy B Hair, Section of Neonatology, Department of Pediatrics, Baylor College of Medicine, Texas Children's Hospital, Houston, TX 77030, USA;

abhair@texaschildrenshospital. org

Received 24 November 2017 Revised 10 July 2018 Accepted 13 October 2018 Published Online First 13 November 2018

\section{SLinked}

- http://dx.doi.org/10.1136/ archdischild-2018-315082

\section{Check for updates}

(C) Author(s) (or their employer(s)) 2019. Re-use permitted under CC BY-NC. No commercial re-use. See rights and permissions. Published by BMJ.

To cite: Visuthranukul $C$ Abrams SA, Hawthorne KM et al. Arch Dis Child Fetal Neonatal Ed

2019;104:F242-F247.

\section{ABSTRACT}

Objective To compare postdischarge growth, adiposity and metabolic outcomes of appropriate for gestational age (AGA) versus small for gestational age (SGA) premature infants fed an exclusive human milk (HM)based diet in the neonatal intensive care unit.

Design Premature infants (birth weight $\leq 1250 \mathrm{~g}$ ) fed an exclusive HM-based diet were examined at 12-15 months corrected gestational age (CGA) (visit 1) for anthropometrics, serum glucose and non-fasting insulin, and at 18-22 months CGA (visit 2) for body composition by dual-energy $\mathrm{X}$-ray absorptiometry.

Results Of 51 children, 33 were AGA and 18 were SGA at birth. The SGA group had weight gain ( $g /$ day) equal to AGA group during the follow-up period. SGA had a significantly greater body mass index (BMI) z-score gain from visit 1 to visit $2(0.25 \pm 1.10$ vs $-0.21 \pm 0.84$, $\mathrm{p}=0.02$ ) reflecting catch-up growth. There were no significant differences in total fat mass (FM) and trunk FM between groups. SGA had significantly lower insulin level $(5.0 \pm 3.7$ vs $17.3 \pm 15.1 \mu \mathrm{U} / \mathrm{mL}, \mathrm{p}=0.02)$ and homeostatic model of assessment-insulin resistance $(1.1 \pm 0.9$ vs $4.3 \pm 4.1, p=0.02)$. Although regional trunk FM correlated with insulin levels in SGA ( $r=0.893$, $p=0.04$ ), they had lower insulin level compared with AGA and no difference in adiposity.

Conclusions SGA premature infants who received an exclusive HM-based diet exhibited greater catch-up growth without increased adiposity or elevated insulin resistance compared with AGA at 2 years of age. An exclusive HM-based diet may improve long-term body composition and metabolic outcomes of premature infants with $\leq 1250 \mathrm{~g}$ birth weight, specifically SGA.

\section{INTRODUCTION}

Mother's own milk has been shown to offer substantial benefits for the health and nutritional status of premature infants. ${ }^{1}$ An entirely human milk (HM)-based diet is composed of mother's milk or donor HM plus a donor HM-derived fortifier and is designed for premature infants in the neonatal intensive care unit (NICU). ${ }^{2}$ Donor HM products have demonstrated multiple benefits to premature infants when compared with a bovine-derived diet, including decreased necrotising enterocolitis, bronchopulmonary dysplasia, retinopathy of prematurity and late-onset sepsis. ${ }^{3}$ In premature infants,

\section{What is already known on this topic?}

- An exclusive human milk (HM)-based diet is designed for premature infants in the neonatal intensive care unit (NICU).

- Very low birth weight (VLBW) infants fed an exclusive HM-based diet had better growth than other HM-fed cohorts and had a low postnatal growth failure rate at discharge.

- Rapid catch-up growth for premature infants, especially small for gestational age (SGA) infants, in early childhood has been linked to metabolic disorders and central adiposity.

\section{What this study adds?}

- VLBW premature appropriate for gestational age (AGA) and SGA children fed an exclusive HM-based diet in the NICU had acceptable growth at 1 and 2 years of age.

- SGA children had greater catch-up growth later without increased adiposity or increased insulin resistance compared with AGA children at 2 years of age.

- An exclusive HM-based diet may improve longterm body composition and metabolic outcomes of VLBW premature infants, especially SGA infants.

growth failure remains a common problem. Thus, a fortifier or a nutrient supplement may be added to the HM or donor HM to provide the total nutritional needs of very low birth weight (VLBW) premature infants. ${ }^{4}$

Hair et al reported that infants with a birth weight $(\mathrm{BW}) \leq 1250 \mathrm{~g}$ fed an exclusive HM-based diet with early and rapid advancement of fortification had better in-hospital growth than other HM-fed cohorts and had a low postnatal growth failure rate at discharge $(43 \%){ }^{5}$ However, rapid catch-up growth for premature infants, especially small for gestational age (SGA) infants, in early childhood has been linked to metabolic disorders and central adiposity. ${ }^{6}$

Singhal et al found that premature infants who received HM compared with formula had less 
association with metabolic syndrome when they reached adolescence. ${ }^{7}$ Insulin resistance in children has also been associated with premature delivery, SGA and rapid catch-up growth in SGA infants at 1 year of age. ${ }^{4-10}$ In adults with cardiovascular disease and type 2 diabetes, postinfancy early childhood weight gain and body mass index (BMI) were important factors for both body fat mass (FM) and consequent diseases. ${ }^{11}$ The role of SGA in insulin resistance remains controversial due to conflicting study findings. Studies have shown that neither SGA nor premature infants confer greater risk of insulin resistance. ${ }^{812}$ Conversely, Bazaes et al found that preterm SGA children showed lower insulin sensitivity compared with their premature appropriate for gestational age (AGA) peers. ${ }^{13}$

No published studies to date have evaluated postdischarge development of total and central body FM and the relationship to insulin resistance in premature SGA children fed an exclusive HM-based diet while in the NICU. Therefore, we assessed and compared longitudinal growth, adiposity and metabolic outcomes of premature AGA and SGA infants who received this exclusive HM-based diet protocol.

\section{METHODS}

This was a single-centre, longitudinal cohort study of premature infants admitted to the NICU of Texas Children's Hospital (Houston, Texas, USA) between August 2010 and December 2011. The inclusion criteria were premature infants with a gestational age (GA) of $<37$ weeks, BW of $\leq 1250 \mathrm{~g}$, fed an exclusive HM-based diet in the NICU until approximately 34 weeks postmenstrual age and ability to maintain their postdischarge follow-up at Texas's Children Hospital. As stated previously, infants were fed a standardised feeding protocol providing an estimated $4 \mathrm{~g} / \mathrm{kg} /$ day of HM protein. This amount was derived from an estimation without using a HM analysis machine. ${ }^{5}$ SGA was defined as <10th percentile on Olsen growth curve. ${ }^{14}$ The exclusion criteria were no enteral feeding by 4 weeks of life, clinically significant congenital heart disease and major congenital anomalies.

The Institutional Review Board of Baylor College of Medicine and Affiliated Hospitals approved this study. Parental written informed consents were obtained, and the infants enrolled into the study. Data were prospectively collected from birth to discharge from the previous study involving this cohort. ${ }^{5}$ Two outpatient study visits took place in the Metabolic Research Unit at the United States Department of Agriculture/Agricultural Research Service Children's Nutrition Research Center between February 2012 and May 2014. The first visit (visit 1) was performed at 12-15 months corrected gestational age (CGA). Parents provided an interim medical history, demographic information, a nutrition history of the infant's overall intake at discharge and a 24 hour dietary recall at visit 1 and visit 2 that were used to calculate energy intake by using Nutrition Data System for Research nutrient analysis software (Minneapolis, Minnesota). ${ }^{15}$ Baseline anthropometric measurements were prospectively collected from the infants including weight, length and head circumference ( $\mathrm{HC})$ using the same scales and length boards. All anthropometric measurements at birth and NICU discharge were assigned corresponding percentiles based on Olsen growth data. ${ }^{14}$ Based on the WHO 2007 growth reference, visit 1 and visit 2 anthropometrics were converted to percentiles for corrected age. ${ }^{16}$ Non-fasting random serum glucose and insulin levels were obtained at visit 1 . Non-fasting homeostatic model of assessment-insulin resistance (HOMA-IR) was calculated from (insulin $\times$ glucose)/22.5. ${ }^{17}$ The second visit (visit 2) was at 18-22 months CGA. Data collection was similar to the first visit, except it included dual-energy X-ray absorptiometry (DXA) but did not include labs. DXA has been extensively studied to evaluate body composition in children and has exhibited high accuracy and precision. ${ }^{18}$ Reference standards already exist for term infants at 12-23 months of age. ${ }^{19} 20$ To evaluate body composition, FM or lean mass (LM) in kilograms divided by the square of height in metres $\left(\mathrm{kg} / \mathrm{m}^{2}\right)$ was used to calculate fat mass index and lean mass index, respectively. ${ }^{21}$

Descriptive statistics were used to summarise all quantitative data. Qualitative data were summarised using proportions and percentages. Continuous variables were reported as mean \pm SD and compared between the AGA and SGA groups by an independent sample t-test, while categorical variables were reported as frequencies and percentages and compared using the $\chi^{2}$ test. A paired t-test was used to test for significant changes at different time points. In order to accommodate the repeated measurements on the same individuals, mixed effects linear models with a first-order autoregressive covariance structure were used to compare AGA versus SGA patients' weight, length and HC percentiles over time (birth, discharge, visit 1 and visit 2). We evaluated the correlation between growth, body composition and insulin level in each group and assessed the relationship of growth with the parameters of body composition and insulin level using Pearson's correlation coefficient. Linear regression analysis was used to compare SGA with AGA patients after adjusting for gestational age (GA) and diet at discharge. Statistical significance was defined as a $\mathrm{p}$ value $<0.05$. Analyses were completed using SPSS V.22.0.

\section{RESULTS}

Fifty-one infants were enrolled in this study, with 33 infants in the AGA group and 18 in the SGA group. The interim medical history, demographic data, nutrition history of the infant's overall intake at discharge and 24 hours dietary recalls at visit 1 and visit 2, as well as baseline characteristics of AGA and SGA infants, are presented in table 1. Energy and nutrients were not significantly different between groups at visit 1 and visit 2 . There were no significant differences in baseline characteristics except GA between groups, and we anticipated that SGA usually have greater GA than AGA infants. A significantly higher proportion of SGA infants were discharged on a diet with breast milk $(\mathrm{p}=0.04)$.

The outcomes at follow-up evaluations are shown in table 2.

The AGA and SGA children had weight gain around 15-20 g/ day during the follow-up period. The SGA group had weight gain (g/day) equal to the AGA group from discharge to visit 1 , and significantly greater BMI $\mathrm{z}$-score gain from visit 1 to visit 2 $(0.25 \pm 1.10$ vs $-0.21 \pm 0.84, p=0.02)$. After controlling for GA and diet at discharge, the SGA group had significantly greater BMI z-score gain from visit 1 to visit $2(\mathrm{p}=0.004$, table 2$)$. Weight and $\mathrm{HC}$ percentiles increased significantly over time in both groups ( $p=0.022$ and $p=0.002$, respectively) (figure 1$)$. Length of stay was significantly associated with weight gain $(\mathrm{g} / \mathrm{kg} / \mathrm{day})$ prior to discharge in the AGA group $\left(\mathrm{R}^{2}=0.312, \mathrm{p}<0.001\right)$ and the SGA group $\left(\mathrm{R}^{2}=0.026, \mathrm{p}<0.001\right)$, but significant associations were not observed at any other time periods.

There was no difference in body composition between the two groups (table 2). Weight gain and length gain in hospital did not correlate with FM but positively correlated with LM in the SGA group $(\mathrm{r}=0.696, \mathrm{p}=0.02$ and $\mathrm{r}=0.671, \mathrm{p}=0.02$, respectively). Interestingly, the SGA children had significantly lower non-fasting insulin level $(\mathrm{p}=0.001)$ and non-fasting HOMA-IR $(\mathrm{p}=0.001)$ 
Table 1 Baseline characteristics and parameter measurements for premature AGA and SGA infants receiving an exclusive human milkbased diet

\begin{tabular}{|c|c|c|c|}
\hline & AGA $(n=33)$ & SGA $(n=18)$ & $P$ values \\
\hline \multicolumn{4}{|l|}{ Gender* } \\
\hline Male & $20(60.6)$ & $10(55.6)$ & 0.77 \\
\hline Female & $13(39.4)$ & $8(44.4)$ & \\
\hline \multicolumn{4}{|l|}{ Race* $^{*}$} \\
\hline White & $7(21.1)$ & $8(44.4)$ & 0.13 \\
\hline Black & $12(36.4)$ & $6(33.3)$ & \\
\hline Hispanic & $12(36.4)$ & $2(11.1)$ & \\
\hline Asian & $2(6.1)$ & $1(5.6)$ & \\
\hline Other & $0(0)$ & $1(5.6)$ & \\
\hline Gestational age (week) $\dagger$ & $26.4 \pm 1.9$ & $29.3 \pm 2.8$ & $<0.001 \ddagger$ \\
\hline Birth weight $(g) \dagger$ & $898.2 \pm 203.7$ & $883.7 \pm 211.3$ & 0.81 \\
\hline Birth length $(\mathrm{cm}) \dagger$ & $34.5 \pm 2.9$ & $33.7 \pm 3.6$ & 0.41 \\
\hline Birth $\mathrm{HC}(\mathrm{cm}) \dagger$ & $23.9 \pm 1.9$ & $24.9 \pm 2.1$ & 0.07 \\
\hline Discharge weight $(\mathrm{g}) \dagger$ & $2850.3 \pm 783.7$ & $2575 \pm 1011.9$ & $0.04 \ddagger$ \\
\hline Discharge length $(\mathrm{cm}) \dagger$ & $46.8 \pm 3.6$ & $45.0 \pm 4.1$ & 0.08 \\
\hline Discharge $\mathrm{HC}(\mathrm{cm}) \dagger$ & $33.1 \pm 2.3$ & $32.8 \pm 2.7$ & 0.64 \\
\hline Length of stay (days) $\dagger$ & $90.9 \pm 40.8$ & $81.4 \pm 47.5$ & 0.34 \\
\hline PMA at discharge (week) $\dagger$ & $39.9 \pm 5.0$ & $41.2 \pm 4.8$ & 0.19 \\
\hline Oxygen at week $36^{*}$ & $12(36.4)$ & $7(38.9)$ & 0.86 \\
\hline NEC, septic ileus and others* & $3(9.1)$ & 0 & 0.19 \\
\hline $\begin{array}{l}\text { Rate of spontaneous intestinal } \\
\text { perforation* }\end{array}$ & $1(3)$ & 0 & 0.46 \\
\hline Drains for perforation* & $1(3)$ & 0 & 0.46 \\
\hline $\begin{array}{l}\text { Diet at discharge with breast } \\
\text { milk*}^{*}\end{array}$ & $14(42.4)$ & $13(72.2)$ & $0.04 \ddagger$ \\
\hline Energy at visit 1 (kcal/day)† & $1314 \pm 417.1$ & $1251 \pm 399.8$ & 0.60 \\
\hline Carbohydrate at visit 1 (g/day) $\dagger$ & $174.5 \pm 67.5$ & $154.1 \pm 62.6$ & 0.35 \\
\hline Protein at visit 1 (g/day)† & $50.6 \pm 18.7$ & $52.4 \pm 25.3$ & 0.95 \\
\hline Fat at visit 1 (g/day) $\dagger$ & $53.8 \pm 42.1$ & $47.8 \pm 16.8$ & 0.99 \\
\hline Energy at visit 2 (kcal/day) $\dagger$ & $1332 \pm 301.9$ & $1396 \pm 318.9$ & 0.25 \\
\hline Carbohydrate at visit 2 (g/day) $\dagger$ & $169.1 \pm 50.4$ & $167.1 \pm 43.2$ & 0.99 \\
\hline Protein at visit 2 (g/day) $\dagger$ & $54.9 \pm 15.0$ & $63.9 \pm 26.7$ & 0.16 \\
\hline Fat at visit 2 (g/day) $\dagger$ & $49.3 \pm 12.9$ & $53.4 \pm 18.0$ & 0.38 \\
\hline
\end{tabular}

${ }^{*} \mathrm{n}(\%), \chi^{2}$ test $\mathrm{p}$ values.

†Mean $\pm S D$, independent samples t-test $p$ values.

$¥$ Statistically significant difference.

AGA, appropriate for gestational age; $\mathrm{HC}$, head circumference; NEC, necrotising enterocolitis; PMA, postmenstrual age; SGA, small for gestational age.

compared with the AGA children (table 2). Moreover, regression analysis showed significant difference in the change of insulin level and HOMA-IR between groups after adjusting for GA and diet at discharge $(p=0.02)$. The mean glucose levels were significantly lower for SGA infants $(\mathrm{p}=0.03)$ in the bivariate analysis; however, the association just misses the cut-off for significance $(\alpha=0.05)$ after adjusting for GA and diet at discharge $(p=0.06$, table 2). There were no significant correlations between rates of catch-up growth and insulin level. In the SGA group, there was a positive correlation between regional trunk FM and insulin levels $(\mathrm{r}=0.893, \mathrm{p}=0.042)$. However, these correlations were not observed in the AGA group (figure 2 ).

\section{DISCUSSION}

We have previously reported that premature infants $\leq 1250 \mathrm{~g}$ BW fed an exclusive HM-based diet showed superior in-hospital growth ${ }^{5}$; this follow-up study assessed long-term outcomes of the cohort. These infants had a lower rate of postnatal growth failure compared with the reference values derived from VLBW infants fed HM and donor HM. ${ }^{22-24}$ To the best of our knowledge, this is the first study evaluating long-term postdischarge growth, adiposity and insulin resistance of AGA and SGA premature infants who received an exclusive HM-based diet.

In our study, the AGA and SGA children had an acceptable growth based on the increase in weight (g/day) and BMI z score per WHO growth standards as well as weight, length and HC percentiles. ${ }^{162526}$ Figure 1 shows that SGA and AGA infants had catch-up growth over time and did not have growth failure (weight $<10$ th percentile) at 1 and 2 years of age, suggesting that these infants received adequate nutrients and energy from the exclusive HM feeding protocol in the NICU and after hospital discharge, resulting in subsequent adequate catch-up growth. The AGA children had equal weight gain to the SGA children from discharge to visit 1, while the SGA group significantly gained more BMI z-score from visit 1 to visit 2 . These findings likely reflect that the SGA children were still achieving catch-up growth until 18-22 months CGA. Similarly to our study, previous reports demonstrated SGA children mainly completed their catch-up growth and weight gain by 2 years. ${ }^{27} 28$ Nonetheless, some studies have reported that SGA infants failed to achieve catch-up growth within 12 months CGA and had weight impairment at 2 years, irrespective of feeding protocol. ${ }^{29} 30$

We evaluated body composition and its associations with growth in preterm infants because preterm delivery and rapid postnatal weight gain have been shown to be associated with a high risk of adiposity. ${ }^{27}$ We found that SGA infants had catch-up growth later without greater adiposity than AGA infants, without significant differences in total FM and trunk FM between both groups. Weight gain and length gain in hospital did not correlate with FM but positively correlated with LM in the SGA group. These findings suggest that more appropriate growth with increase in weight and length gain in the immediate postnatal period possibly led to a leaner body composition, perhaps decreasing the likelihood of developing insulin resistance and diabetes later in life. Furthermore, they had adequate bone mineralisation as well as FM and LM comparable with those measured in age-matched term infants. ${ }^{19} 2031$ A study in preterm AGA and SGA infants in Chile showed weight gain after term CGA positively correlated with FM and percentage of trunk FM at 6 years. Similarly to our study, their results of body composition were comparable between both groups; however, they found lower LM in SGA compared with AGA children. ${ }^{32}$ Other studies have reported SGA children accumulated more body and abdominal fat compared with AGA children. ${ }^{27} 31$ Such early changes in SGA infants may increase the risk of long-term effects, including excessive total body and abdominal fat linked with insulin resistance, diabetes and cardiovascular disease in adults. ${ }^{33}$ We find it reassuring that SGA and AGA children in our cohort had similar body composition at 2 years of age and SGA children achieved catch-up growth without increased adiposity.

A relationship has been shown to exist between adiposity and insulin resistance in SGA infants. ${ }^{34}$ The SGA children might have changes in stature and body composition, especially increased FM; these may be factors in the pathogenesis of insulin resistance. ${ }^{35}$ The regional trunk FM correlated with serum insulin levels in SGA infants; however, SGA infants still had significantly lower insulin levels compared with AGA infants and no difference in adiposity. We anticipated that SGA infants might not have metabolic consequences in the near future.

One of our main findings is that the SGA children had a significant lower insulin level compared with the AGA children. When compared with the insulin levels in the preterm children at 1.4 
Table 2 Growth, growth velocity, body composition, non-fasting glucose, insulin level and HOMA-IR of premature AGA and SGA infants during follow-up visits (mean \pm SD for each group)

\begin{tabular}{|c|c|c|c|c|}
\hline & AGA $(n=33)$ & SGA $(n=18)$ & Unadjusted P values* & Adjusted P valuest \\
\hline \multicolumn{5}{|l|}{ Visit 1} \\
\hline Corrected age (months) & $14.1 \pm 1.0$ & $13.9 \pm 1.0$ & 0.31 & 0.50 \\
\hline Weight (kg) & $9.6 \pm 1.2$ & $8.2 \pm 1.2$ & $<0.001 \ddagger$ & $0.008 \ddagger$ \\
\hline Length $(\mathrm{cm})$ & $76.6 \pm 3.4$ & $73.1 \pm 3.0$ & $<0.001 \ddagger$ & $0.004 \ddagger$ \\
\hline BMI z-score & $-0.1 \pm 1.1$ & $-0.98 \pm 1.4$ & $0.02 \ddagger$ & 0.18 \\
\hline $\mathrm{HC}(\mathrm{cm})$ & $46.0 \pm 1.6$ & $44.8 \pm 1.5$ & $0.01 \ddagger$ & $0.04 \ddagger$ \\
\hline \multicolumn{5}{|l|}{ Visit 2} \\
\hline Corrected age (months) & $19.2 \pm 1.2$ & $19.9 \pm 1.4$ & 0.06 & 0.05 \\
\hline Weight (kg) & $10.7 \pm 1.2$ & $9.7 \pm 1.4$ & $0.02 \ddagger$ & 0.15 \\
\hline Length $(\mathrm{cm})$ & $82.8 \pm 4.6$ & $80.0 \pm 5.3$ & 0.07 & 0.05 \\
\hline BMI z-score & $-0.38 \pm 1.4$ & $-0.77 \pm 1.4$ & 0.38 & 0.71 \\
\hline $\mathrm{HC}(\mathrm{cm})$ & $47.1 \pm 1.7$ & $46.2 \pm 1.6$ & 0.11 & 0.23 \\
\hline \multicolumn{5}{|l|}{ Discharge to visit 1} \\
\hline Days from discharge & $433.2 \pm 40.5$ & $413.2 \pm 45.8$ & 0.11 & $0.01 \ddagger$ \\
\hline Change in weight (g/day) & $15.5 \pm 3.6$ & $13.5 \pm 2.6$ & 0.05 & 0.05 \\
\hline Change in length (cm/week) & $0.48 \pm 0.1$ & $0.48 \pm 0.1$ & 0.86 & 0.49 \\
\hline Change in $\mathrm{HC}$ ( $\mathrm{cm} /$ week) & $0.21 \pm 0.04$ & $0.20 \pm 0.03$ & 0.64 & $0.04 \ddagger$ \\
\hline \multicolumn{5}{|l|}{ Visit 1 to visit 2} \\
\hline Days from visit 1 & $152.9 \pm 39.5$ & $186.3 \pm 55.3$ & $0.03 \ddagger$ & $0.03 \ddagger$ \\
\hline Change in weight (g/day) & $23.2 \pm 14.4$ & $20.5 \pm 14.9$ & 0.53 & 0.26 \\
\hline Change in length (cm/week) & $0.28 \pm 0.16$ & $0.24 \pm 0.11$ & 0.37 & 0.13 \\
\hline Change in $\mathrm{HC}(\mathrm{cm} /$ week) & $0.05 \pm 0.03$ & $0.05 \pm 0.02$ & 0.78 & 0.65 \\
\hline Change in BMI z-score & $-0.21 \pm 0.84$ & $0.25 \pm 1.10$ & $0.02 \ddagger$ & $0.004 \ddagger$ \\
\hline \multicolumn{5}{|l|}{ DXA (whole body scan)§ } \\
\hline BMC (g) & $361.6 \pm 38.5$ & $351.8 \pm 44.9$ & 0.51 & 0.77 \\
\hline $\mathrm{BMD}\left(\mathrm{g} / \mathrm{cm}^{2}\right)$ & $0.46 \pm 0.03$ & $0.46 \pm 0.04$ & 0.71 & 0.80 \\
\hline $\mathrm{FM}(\mathrm{kg})$ & $3.3 \pm 0.7$ & $3.1 \pm 1.1$ & 0.68 & 0.53 \\
\hline $\mathrm{FMI}\left(\mathrm{kg} / \mathrm{m}^{2}\right)$ & $4.7 \pm 1.1$ & $4.8 \pm 1.6$ & 0.87 & 0.94 \\
\hline LM (kg) & $7.3 \pm 0.8$ & $6.9 \pm 0.6$ & 0.14 & 0.74 \\
\hline LMI $\left(\mathrm{kg} / \mathrm{m}^{2}\right)$ & $10.5 \pm 1.2$ & $10.6 \pm 1.2$ & 0.91 & 0.16 \\
\hline$\%$ Fat & $30 \pm 4.8$ & $29.8 \pm 6.4$ & 0.91 & 0.41 \\
\hline Regional trunk FM (kg) & $1.1 \pm 0.3$ & $1.1 \pm 0.5$ & 0.73 & 0.39 \\
\hline Regional trunk FMI $\left(\mathrm{kg} / \mathrm{m}^{2}\right)$ & $1.6 \pm 0.4$ & $1.7 \pm 0.6$ & 0.97 & 0.74 \\
\hline Regional trunk LM (kg) & $3.4 \pm 0.5$ & $3.2 \pm 0.3$ & 0.29 & 0.93 \\
\hline Regional trunk LMI $\left(\mathrm{kg} / \mathrm{m}^{2}\right)$ & $4.9 \pm 0.7$ & $5.0 \pm 0.6$ & 0.73 & 0.13 \\
\hline Regional trunk \%fat (\%) & $24.4 \pm 5.5$ & $23.9 \pm 7.0$ & 0.82 & 0.33 \\
\hline Glucose (mmol/L)ף & $5.3 \pm 0.5$ & $4.9 \pm 0.4$ & $0.03 \ddagger$ & 0.06 \\
\hline Insulin $(\mu \mathrm{U} / \mathrm{mL})$ ๆ & $17.3 \pm 15.1$ & $5.0 \pm 3.7$ & $0.02 \ddagger$ & $0.02 \ddagger$ \\
\hline HOMA-IRף & $4.3 \pm 4.1$ & $1.1 \pm 0.9$ & $0.02 \ddagger$ & $0.02 \ddagger$ \\
\hline
\end{tabular}

*Independent samples t-test $\mathrm{p}$ values.

tLinear regression $p$ value after adjusting for gestational age and diet at discharge.

¥Statistically significant difference.

§For DXA whole body scan measurements, $\mathrm{n}=23$ for AGA infants and $\mathrm{n}=11$ for SGA infants.

IFor non-fasting glucose, insulin and HOMA-IR, $n=19$ for AGA infants and $n=10$ for SGA infants.

AGA, appropriate for gestational age; BMC, bone mineral content; BMD, bone mineral density; BMI, body mass index; DXA, dual-energy X-ray absorptiometry; FM, fat mass; FMI, fat mass index; HC, head circumference; HOMA-IR, homeostatic model of assessment-insulin resistance; LM, lean mass; LMI, lean mass index; SGA, small for gestational age.

years of age from another study, the insulin levels in our SGA children were lower, while insulin levels in the AGA children were slightly higher. This is possibly due to the lower GA of the AGA infants in our study as Wang et al showed that plasma insulin levels in early childhood were inversely associated with GA. ${ }^{36}$ These findings suggest an exclusive HM-based diet in the NICU could lead to favourable metabolic outcomes in SGA children. Previous studies have shown no difference in insulin resistance between preterm AGA and SGA infants, possibly due to minimal metabolic effect from an intrauterine restriction before the third trimester of pregnancy. ${ }^{8}{ }^{12}$ Nevertheless, other studies showed that preterm SGA had higher insulin resistance than preterm AGA children. ${ }^{913}$ Some studies have shown fasting insulin levels were mainly associated with weight gain rates early in life. ${ }^{1037}$ However, weight and length gains in any periods of our study did not have significantly positive correlations with insulin levels. Thus, we contend that catch-up growth in the SGA group did not lead to increased insulin resistance. Due to the difference of GA and diet at discharge between the two groups, we did general linear model to adjust for GA and diet at discharge. The GA and diet at discharge had no greater effects on the classification of the two groups. The lower insulin level 




Figure 1 Weight, length and HC percentiles of infants at birth and discharge using Olsen growth data ${ }^{14}$ and at 12-15 months CGA and 18-22 months CGA using WHO growth data. ${ }^{16}$ Weight percentile was significantly lower over time for SGA patients compared with AGA patients $(p<0.001)$, and it increased significantly over time in both groups $(p=0.022)$. Length percentile was significantly lower over time for $S G A$ patients compared with AGA patients $(p<0.001)$ and did not change significantly over time $(p=0.582)$. HC percentile was significantly lower over time for $S G A$ patients compared with AGA patients $(p=0.002)$, and it increased significantly over time in both groups $(p=0.002)$. AGA, appropriate for gestational age; CGA, corrected gestational age; HC, head circumference; SGA, small for gestational age.

and HOMA-IR were demonstrated in the SGA group. These findings suggest that the exclusive HM-based diet could have more beneficial effect on insulin level in the SGA children.

The strength of this study is that it is the first to evaluate longterm postdischarge growth, adiposity and non-fasting random insulin levels in VLBW premature infants fed an exclusive HM-based diet in the NICU, and the outcomes were compared between VLBW preterm AGA and SGA infants. Additionally, the relationship of growth with the parameters of body composition and insulin levels were assessed to determine the effects of this diet protocol on these two different groups. We did not have control groups of term AGA and term SGA infants to compare with our subjects to clearly determine insulin levels or sensitivity in preterm AGA and SGA infants to indicate that increase or decrease metabolic risk surrogates are due to prematurity alone or this diet protocol. Additionally, the infants' fasting blood sugar and insulin levels were not obtained due to the invasive nature of this procedure and the difficulty of obtaining results in young children. Therefore, HOMA-IR, which is a marker for insulin resistance, was from a non-fasting condition. However, a tendency of difference in insulin resistance could be determined between both groups. In addition, another potential limitation is

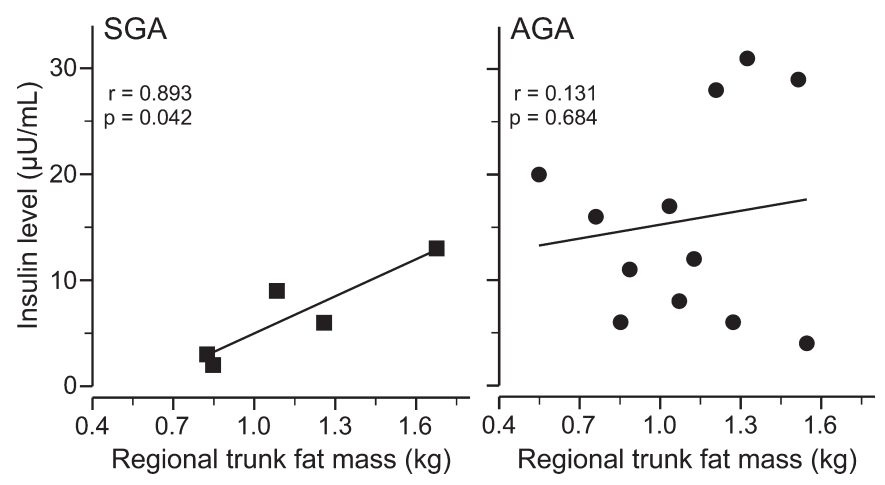

Figure 2 Correlations between regional trunk fat mass with insulin levels in the AGA and SGA groups. The regional trunk fat and insulin levels were shown as the preliminary data from both groups. Five SGA infants and 12 AGA infants had both DXA and insulin results. The missing data occurred due to the difficulty of obtaining these results in young children. AGA, appropriate for gestational age; DXA, dual-energy X-ray absorptiometry; SGA, small for gestational age. selection bias, as infants were included in the study only if they were able to return for the follow-up at our institution.

In conclusion, VLBW premature AGA and SGA children who received an exclusive HM-based diet in the NICU, which provides high protein, had acceptable growth at 1 and 2 years of age as evidenced by weight gain per WHO standards and growth percentiles well above the 10th percentile. SGA children had greater catch-up growth later without increased adiposity or increased insulin resistance compared with AGA children at 2 years of age. These results suggest that an exclusive HM-based diet may improve long-term body composition and metabolic outcomes of VLBW premature infants, especially SGA infants.

Correction notice This article has been updated since its first publication to correct minor typographical errors present in the main text.

Acknowledgements We would like to thank the following people for their invaluable assistance with the project: Marie Turcich, Maryse Laurent, Vilma Cardova, Janice Betancourt, Dr Lynda Tang and Michael LeCompte. We would like to thank the Bad Pants Open Fund at Texas Children's Hospital for supporting this project.

Contributors $\mathrm{CV}$ was part of the study design team, assisted in all aspects of the study, performed the statistical analysis of the data and wrote the manuscript. SAA was part of the study design team, assisted in all aspects of the study and preparation of the manuscript. KMH was part of the study design team and assisted in all aspects of the study.JLH was part of statistical analysis. ABH was part of the study design team, assisted in all aspects of the study including recruitment, data analysis, statistical analysis and preparation of the manuscript.

Funding The Texas Children's Hospital Bad Pants Open Fund.

Competing interests $\mathrm{KMH}$ : receives speaker honoraria from Prolacta Bioscience. ABH receives research support from Prolacta Bioscience for the Human Milk Cream Length of Stay Randomized Trial and the Human Milk Cardiac Study.

Patient consent Parental/guardian consent obtained.

Ethics approval The Institutional Review Board of Baylor College of Medicine and Affiliated Hospitals approved this study.

Provenance and peer review Not commissioned; externally peer reviewed.

Open access This is an open access article distributed in accordance with the Creative Commons Attribution Non Commercial (CC BY-NC 4.0) license, which permits others to distribute, remix, adapt, build upon this work non-commercially, and license their derivative works on different terms, provided the original work is properly cited, appropriate credit is given, any changes made indicated, and the use is non-commercial. See: http://creativecommons.org/licenses/by-nc/4.0/.

\section{REFERENCES}

1 Morales Y, Schanler RJ. Human milk and clinical outcomes in VLBW infants: how compelling is the evidence of benefit? Semin Perinato/ 2007;31:83-8. 
2 Sullivan S, Schanler RJ, Kim JH, et al. An exclusively human milk-based diet is associated with a lower rate of necrotizing enterocolitis than a diet of human milk and bovine milk-based products. J Pediatr 2010;156:562-7.

3 Hair AB, Peluso AM, Hawthorne KM, et al. Beyond necrotizing enterocolitis prevention: improving outcomes with an exclusive human milk-based diet. Breastfeed Med 2016;11:70-4.

4 Schanler RJ. Outcomes of human milk-fed premature infants. Semin Perinatol 2011;35:29-33

5 Hair $A B$, Hawthorne KM, Chetta KE, et al. Human milk feeding supports adequate growth in infants $\leq 1250$ grams birth weight. BMC Res Notes 2013;6:459.

6 Veening MA, Van Weissenbruch MM, Delemarre-Van De Waal HA. Glucose tolerance, insulin sensitivity, and insulin secretion in children born small for gestational age. J Clin Endocrinol Metab 2002:87:4657-61.

7 Singhal A, Cole TJ, Lucas A. Early nutrition in preterm infants and later blood pressure: two cohorts after randomised trials. Lancet 2001;357:413-9.

8 Hofman PL, Regan F, Jackson WE, et al. Premature birth and later insulin resistance. N Engl J Med 2004;351:2179-86.

9 Kistner A, Rakow A, Legnevall L, et al. Differences in insulin resistance markers between children born small for gestational age or born preterm appropriate for gestational age. Acta Paediatr 2012;101:1217-24.

10 Soto N, Bazaes RA, Peña V, et al. Insulin sensitivity and secretion are related to catch-up growth in small-for-gestational-age infants at age 1 year: results from a prospective cohort. J Clin Endocrinol Metab 2003;88:3645-50.

11 Bhargava SK, Sachdev HS, Fall CH, et al. Relation of serial changes in childhood body-mass index to impaired glucose tolerance in young adulthood. N Eng/ J Med 2004;350:865-75.

12 Darendeliler F, Bas F, Bundak R, et al. Insulin resistance and body composition in preterm born children during prepubertal ages. Clin Endocrinol 2008;68:773-9.

13 Bazaes RA, Alegría A, Pittaluga E, et al. Determinants of insulin sensitivity and secretion in very-low-birth-weight children. J Clin Endocrinol Metab 2004;89:1267-72.

14 Olsen IE, Groveman SA, Lawson ML, et al. New intrauterine growth curves based on United States data. Pediatrics 2010;125:e214-24.

15 Schakel SF. Maintaining a nutrient database in a changing marketplace: keeping pace with changing food products - a research perspective. Journal of Food Composition and Analysis 2001;14:315-22.

16 World Helath Organization. Child growth standards, The WHO child growth standards. 2007. http://www.who.int/childgrowth/standards/en/

17 Wallace TM, Levy JC, Matthews DR. Use and abuse of HOMA modeling. Diabetes Care 2004;27:1487-95

18 Ellis KJ, Shypailo RJ, Pratt JA, et al. Accuracy of dual-energy x-ray absorptiometry for body-composition measurements in children. Am J Clin Nutr 1994;60:660-5.

19 Butte NF, Hopkinson JM, Wong WW, et al. Body composition during the first 2 years of life: an updated reference. Pediatr Res 2000;47:578-85.
20 Specker BL, Brazerol W, Tsang RC, et al. Bone mineral content in children 1 to 6 years of age. Detectable sex differences after 4 years of age. Am J Dis Child 1987;141:343-4.

21 Wells JC, Cole TJ. ALSPAC study steam. Adjustment of fat-free mass and fat mass for height in children aged 8 y. Int J Obes Relat Metab Disord 2002;26:947-52.

22 Fomon SJ, Haschke F, Ziegler EE, et al. Body composition of reference children from birth to age 10 years. Am J Clin Nutr 1982;35:1169-75.

23 Vohr BR, Poindexter BB, Dusick AM, et al. Beneficial effects of breast milk in the neonatal intensive care unit on the developmental outcome of extremely low birth weight infants at 18 months of age. Pediatrics 2006;118:e115-23.

24 Lucas A, Morley R, Cole TJ, et al. A randomised multicentre study of human milk versus formula and later development in preterm infants. Arch Dis Child Fetal Neonatal Ed 1994;70:F141-6.

25 Chan DK. Enteral nutrition of the very low birth weight (VLBW) infant. Ann Acad Med Singapore 2001:30:174-82.

26 Pauls J, Bauer K, Versmold H. Postnatal body weight curves for infants below $1000 \mathrm{~g}$ birth weight receiving early enteral and parenteral nutrition. Eur J Pediatr 1998;157:416-21.

27 Ibáñez L, Ong K, Dunger DB, et al. Early development of adiposity and insulin resistance after catch-up weight gain in small-for-gestational-age children. J Clin Endocrinol Metab 2006;91:2153-8.

28 Ibáñez L, Lopez-Bermejo A, Diaz M, et al. Catch-up growth in girls born small for gestational age precedes childhood progression to high adiposity. Fertil Steril 2011;96:220-3.

29 Bertino E, Coscia A, Mombrò M, et al. Postnatal weight increase and growth velocity of very low birthweight infants. Arch Dis Child Fetal Neonatal Ed 2006;91:F349-56.

30 Campos M, Reyes G, García L. Comparison of postdischarge growth in adequate for gestational age and small for gestational age very low birthweight infants. Ethn Dis 2008;18(Suppl 2):118-22.

31 Ibáñez L, Suárez L, Lopez-Bermejo A, et al. Early development of visceral fat excess after spontaneous catch-up growth in children with low birth weight. J Clin Endocrinol Metab 2008;93:925-8.

32 Sepúlveda C, Urquidi C, Pittaluga E, et al. Differences in body composition and resting energy expenditure in childhood in preterm children born with very low birth weight. Horm Res Paediatr 2013;79:347-55.

33 Argente J, Mehls 0 , Barrios V. Growth and body composition in very young SGA children. Pediatr Nephrol 2010;25:679-85.

34 Griffin IJ, Cooke RJ. Development of whole body adiposity in preterm infants. Early Hum Dev 2012;88(Suppl 1):S19-24.

35 Tappy L. Adiposity in children born small for gestational age. Int J Obes 2006;30(Suppl 4):S36-40.

36 Wang G, Divall S, Radovick S, et al. Preterm birth and random plasma insulin levels at birth and in early childhood. JAMA 2014;311:587-96.

37 Mericq V, Ong KK, Bazaes $\mathrm{R}$, et al. Longitudinal changes in insulin sensitivity and secretion from birth to age three years in small- and appropriate-for-gestational-age children. Diabetologia 2005:48:2609-14. 